\title{
DIGESTIBILIDADE DE FARINHAS DE COPRODUTOS DE ABACAXI, MANGA E MARACUJÁ PELO TAMBAQUI (Colossoma macropomum)
}

\author{
D. M. ARAUJO ${ }^{1}$, A. M. BORDINHON ${ }^{2}$, R. Y. FUJIMOTO ${ }^{3}$, W. M. DA SILVA ${ }^{4}$, D. R. DA SILVA ${ }^{5}$, J. DA SILVA \\ Instituto Federal de Alagoas ${ }^{1,6}$, Universidade Federal do Amazonas ${ }^{2,4}$, EMBRAPA Tabuleiros Costeiros ${ }^{3}$, \\ Universidade Estadual Paulista Júlio de Mesquita Filho ${ }^{5}$ \\ daniel.araujo@ifal.edu.br1 ${ }^{1}$
}

Submetido 07/01/2020 - Aceito 06/08/2020

DOI: $10.15628 /$ holos.2020.9380

\section{RESUMO}

O objetivo com o estudo foi estimar os valores digestíveis de nutrientes e energia de coprodutos oriundos da fabricação de polpas de frutas (abacaxi, manga e maracujá) pelo tambaqui (Colossoma macropomum), por meio da determinação dos respectivos coeficientes de digestibilidade aparentes (CDAs). Os animais experimentais (72 indivíduos, peso médio 70,5 $\pm 15,5 \mathrm{~g}$ ) foram distribuídos em 12 tanques, com $1 \mathrm{~m} 3$ de volume de água, numa distribuição totalmente casualizada, com três repetições por tratamento. Com intuito de obter o valor digestível dos coprodutos da fabricação de polpas produziu-se quatro rações experimentais: Basal, Abacaxi (30\% farinha de abacaxi $+70 \%$ ração Basal), Manga (30\% farinha de manga $+70 \%$ ração Basal), Maracujá $(30 \%$ farinha de maracujá + 70\% ração Basal). Os peixes foram mantidos nos tanques de alimentação durante o dia. Nestes tanques os animais foram alimentados ad libitum às 9:00,11:00, 14:00, 15:00, 16:00 e 17:00 h. Às 18:00 h os animais foram transferidos para tanques cônicos de 200 L, adaptados para decantação e coleta das fezes na manhã do dia seguinte. Os CDAs dos coprodutos de abacaxi, manga e maracujá foram: 57,26; 69,65 e 30,48\% para a matéria seca; 82,$26 ; 66,61$ e $86,07 \%$ para a proteína bruta; 53,25; 57,21 e 19,94\% para a energia bruta. Os baixos valores de energia digestível, principalmente para o maracujá, somados aos altos níveis de fibra bruta, são fatores limitantes ao uso destes ingredientes em rações comerciais para peixes.

PALAVRAS-CHAVE: Alimento alternativo; Nutrição de peixes; Nutrientes digestíveis; Resíduos de frutas; Valor nutricional.

\section{PNEAPLE, MANGO AND PASSION FRUIT BY-PRODUCT BRANS DIGESTIBILITY BY TAMBAQUI (Colossoma macropomum)}

\begin{abstract}
The purpose of the study was to estimate de digestible values of nutrients and energy of fruit pulp byproducts (pineapple, mango and passion fruit) through determining their respective apparent digestibility coefficients (CDAs). Experimental animals (Seventy-two tambaqui juvenile, average weight $70,5 \pm 15,5 \mathrm{~g}$ ) were confined in 12 feeding tanks (water volume $1 \mathrm{~m} 3$ ) in a completely ramdom distribution with three repetition per treatment. In order to obtain digestible values of the byproducts four experimental feeds were produced: Basal, Pineapple $(30 \%$ pineapple pulp production byproduct $+70 \%$ Basal feed), Mango ( $30 \%$ mango pulp production byproduct $+70 \%$ Basal feed) and Passion fruit (30\% passion fruit pulp production byproduct $+70 \%$ Basal feed). Experimental fish were kept in feeding tanks during the day where they were fed ad libitum at: 9am, 11am,
\end{abstract}

$2 \mathrm{pm}, 3 \mathrm{pm}, 4 \mathrm{pm}$ and $5 \mathrm{pm}$. At $6 \mathrm{pm}$ fish were transferred to conic $200 \mathrm{~L}$ water tanks adapted to precipitation of solids where they were stayed until feces collection in the following morning. Apparent digestible coefficients of pineapple, mango and passion fruit byproducts were, respectively: $57.26 ; 69.65$ and $30,48 \%$ for dry matter; $82.26 ; 66.61$ and $86.07 \%$ for crude protein; $53.25 ; 57.21$ and $19.94 \%$ for crude energy. Digestible energy low values, of passion fruit byproduct in special, allied to high levels of fiber may represent limiting factors to the usage of those ingredients in commercial fish feeds.

KEYWORDS: Alternative feedstuff; Fish nutrition; Digestible nutrients; Fruit byproducts; Nutritional values. 


\section{INTRODUÇÃO}

A agropecuária brasileira possui reconhecimento internacional pela sua capacidade tecnológica e de inovação, pela sua escala de produção e seus índices de produtividade, permitindo que o Brasil se consolide como um dos maiores produtores mundiais de alimentos, estando na vanguarda da produção vegetal e animal. Nesta condição de destaque na produção de alimentos no mundo, o Brasil possui proporcional cadeia produtiva de beneficiamento de produtos agrícolas. Assim, há um enorme desafio em gerenciar adequadamente imensos volumes de coprodutos oriundos das agroindústrias, e dentro destas estratégias para lidar com este problema está a incorporação destes como ingredientes de fórmulas alimentícias para animais.

A produção de frutas é uma das áreas da atividade agropecuária em que o Brasil tem se destacado. No país há uma imensa diversidade de frutas tropicais nativas que, somadas às frutas exóticas produzidas comercialmente em larga escala, fazem do Brasil o terceiro maior produtor mundial de frutas, precedido por China e Índia, conforme o Anuário Brasileiro de Fruticultura (KIST et al., 2018). De acordo com este anuário, o país produziu 43,5 milhões de toneladas em 2017 e o processamento destas frutas para a preparação de produtos alimentícios, tais quais geleias, doces, frutas secas, sucos e polpas de frutas gera um excedente de material orgânico usualmente tratado como resíduo. Este material possui potencial para beneficiamento e transformação, dentre outros, para produção de ingredientes para alimentação animal.

Ainda no contexto da produção agropecuária no país, mas em condições relativamente incipientes se comparadas às outras atividades de produção vegetal e animal, a piscicultura brasileira tem apresentado avanços relativos à sua profissionalização e sua consolidação como atividade, principalmente se considerarmos a criação de espécies piscícolas de água doce. 0 tambaqui (Colossoma macropomum), nativo dos rios e lagos da Amazônia, é a terceira espécie de peixe mais produzida no país, presente em estabelecimentos aquícolas em todas as regiões do país (IBGE, 2015).

Como a piscicultura é uma atividade agropecuária de crescente importância econômica, esta demanda soluções inovadoras para o aumento de sua eficiência produtiva. Neste processo faz-se necessário buscar alternativas que promovam melhorias em termos de nutrição e alimentação com a utilização de novos ingredientes. Dentro desta perspectiva, a utilização dos coprodutos oriundos do processamento de frutas para alimentação de peixes pode ser benéfica para ambas as atividades. Para a fruticultura, possibilita a composição de preços ao que seria um resíduo e reduz o potencial poluente do material orgânico; enquanto, para a piscicultura, possibilita aumentar a quantidade de ingredientes disponíveis para a fabricação de rações e a busca pela redução dos custos com alimentação, fator que mais onera a produção.

Tomando-se por base a importância da caracterização da composição nutricional e a determinação da digestibilidade dos nutrientes de novos ingredientes para sua validação para uso na alimentação dos peixes, com o presente estudo, objetivou-se produzir, caracterizar a bromatologia e determinar os coeficientes de digestibilidade aparente dos nutrientes e energia de farinhas de coprodutos de abacaxi, manga e maracujá pelos tambaquis. 


\section{METODOLOGIA}

Os coprodutos do processamento de abacaxi, manga e maracujá, respectivamente, farelo de abacaxi, farelo de manga e farelo de maracujá, foram obtidos diretamente da fábrica da empresa de processamento de frutas, localizada em Cidade - Estado. Após a produção de polpas das frutas, os coprodutos foram coletados, embalados em sacos plásticos (cerca de $100 \mathrm{a} 120 \mathrm{~kg}$ de cada fruta) e congelados ainda na indústria. Após congelamento, estes foram transportados ao Laboratório de Aquicultura e Ambiente Aquático do Instituto Federal de Alagoas, Campus Satuba. Neste laboratório, os alimentos a serem testados foram descongelados, colocados em bandejas metálicas e secos em estufa de recirculação forçada de ar em temperatura de $55^{\circ} \mathrm{C}$ por 48 horas. Após o período de secagem, foram resfriados em temperatura ambiente, moídos em moinho de facas até as partículas atingirem diâmetro igual ou inferior a $500 \mu \mathrm{m}$, homogeneizados, novamente ensacados, identificados e armazenados em freezer a $-20^{\circ} \mathrm{C}$ até posteriores análises de amostras e utilização para a fabricação das rações experimentais.

Para a confecção das rações (Tabela 1) todos ingredientes foram moídos (500 $\mu \mathrm{m}$ ), homogeneizados, umedecidos em água a $65^{\circ} \mathrm{C}$ e esta mistura foi processada em extrusora. As rações experimentais foram secas em estufa de ventilação forçada a $55{ }^{\circ} \mathrm{C}$ pelo período de 24 horas. Após a retirada da estufa e resfriamento em temperatura ambiente, estas foram ensacadas, identificadas e armazenadas em freezer $\left(-20^{\circ} \mathrm{C}\right)$. A todas as misturas para produção das rações foi adicionado 0,50\% de óxido de crômio III que possui função de marcador inerte para determinação do coeficiente de digestibilidade aparente pelo método indireto, de acordo com a metodologia proposta por Cho e Slinger (1979).

Tabela 1. Composição percentual e química das dietas e química dos farelos dos coprodutos de abacaxi, manga e maracujá utilizados na determinação dos coeficientes de digestibilidade aparentes (CDAs) dos ingredientes para juvenis de tambaqui.

\begin{tabular}{lrrrr}
\hline INGREDIENTES & \multicolumn{1}{c}{$\begin{array}{c}\text { Dieta } \\
\text { Referência }\end{array}$} & $\begin{array}{c}\text { Farelo de } \\
\text { Abacaxi }\end{array}$ & $\begin{array}{c}\text { Farelo de } \\
\text { Manga }\end{array}$ & \multicolumn{1}{c}{$\begin{array}{r}\text { Farelo de } \\
\text { Maracujá }\end{array}$} \\
\hline Fubá de milho & 18,00 & 12,60 & 12,60 & 12,60 \\
Farelo de soja & 50,50 & 35,35 & 35,35 & 35,35 \\
Amido de milho & 11,00 & 7,70 & 7,70 & 7,70 \\
Farelo de trigo & 1,40 & 0,98 & 0,98 & 0,98 \\
Farinha de carne & 13,00 & 9,10 & 9,10 & 9,10 \\
Óleo de milho & 2,00 & 1,40 & 1,40 & 1,40 \\
Cloreto de sódio & 1,00 & 0,70 & 0,70 & 0,70 \\
Vitamina C (35\%) & 0,10 & 0,07 & 0,07 & 0,07 \\
Fosfato bicálcico & 2,00 & 1,40 & 1,40 & 1,40 \\
Suplemento vitamínico e mineral & 1,00 & 0,70 & 0,70 & 0,70 \\
Farelo de abacaxi & 0,00 & 30,00 & 0,00 & 0,00 \\
Farelo de manga & 0,00 & 0,00 & 30,00 & 0,00 \\
Farelo de maracujá & 0,00 & 0,00 & 0,00 & 30,00 \\
\hline Total & 100,00 & 100,00 & 100,00 & 100,00 \\
\hline Composição química analisada & \multicolumn{4}{c}{} \\
\hline Matéria seca (\%) & 91,25 & 89,41 & 89,45 & 92,01 \\
Proteína bruta (\%) & 34,45 & 5,01 & 4,39 & 8,73
\end{tabular}

HOLOS, Ano 36, v.5, e9380, 2020 


\begin{tabular}{lrrrr} 
Energia bruta (Kcal/Kg) & 3.933 & 3.829 & 3.892 & 3.697 \\
Extrato etéreo (\%) & 3,77 & 1,57 & 1,82 & 1,96 \\
Matéria mineral (\%) & 12,00 & 2,17 & 2,02 & 6,98 \\
Fibra bruta (\%) & - & 12,87 & 40,78 & 13,38 \\
Extrato não-nitrogenado (\%) & - & 67,79 & 40,44 & 60,96 \\
\hline
\end{tabular}

${ }^{1}$ Os tratamentos 2, 3 e 4 consistem de dietas contendo $70 \%$ da ração referência $+30 \%$ das farinhas de coprodutos de abacaxi, manga e maracujá, respectivamente.

Para determinação dos coeficientes de digestibilidade aparentes (CDAs) dos alimentos foram utilizados doze tanques de alimentação, construídos em alvenaria, de formato retangular e volume de $4 \mathrm{~m}^{3}$, com recirculação e aeração constantes, além de quatro tanques de coleta de fezes, de formato cônico e volume de 200 litros. No período pré-experimental, 100 peixes foram adaptados às condições de ambiente e manejo por 14 dias. No ensaio, foram utilizados 72 juvenis de tambaqui, com peso médio inicial de 70,5 $\pm 15,5 \mathrm{~g}$ e comprimento de 15,4 $\pm 0,85 \mathrm{~cm}$, distribuídos aleatoriamente nos tanques de alimentação (seis peixes por repetição). Os peixes foram mantidos nos tanques de alimentação durante o dia, receberam rações à vontade às 9:00, 11:00, 14:00 e 17:00 h, sendo transferidos às 18:00 $\mathrm{h}$ para os tanques cônicos, visando a decantação e coleta das fezes na manhã do dia seguinte. A cada ciclo de coleta de fezes, todos os tanques, de alimentação ou de coleta de fezes, eram limpos e preparados para novas coletas. 0 monitoramento da qualidade da água ocorreu diariamente para a temperatura (27,05으); a cada dois dias para oxigênio dissolvido $\left(6,20 \mathrm{mg} \mathrm{L}^{-1}\right)$ e $\mathrm{pH}(7,68)$; e semanalmente para a amônia total $\left(0,36 \mathrm{mg} \mathrm{L}^{-1}\right)$; sempre determinados após a primeira e a última oferta de ração.

As análises bromatológicas foram realizadas segundo a AOAC (2005). As análises para determinação da concentração de crômio, das fezes e das rações, foram realizadas segundo Bremer Neto et al. (2005). As análises de energia dos diferentes alimentos, rações e fezes foram realizadas em bomba calorimétrica.

O coeficiente de digestibilidade aparente (CDA) da matéria seca (CDA-MS), proteína bruta (CDA-PB), extrato etéreo (CDA-EE) e matéria mineral (CDA-MM) e energia bruta (CDA-EB) dos alimentos foi calculado com base nas concentrações de óxido de crômio-III, de acordo com a seguinte fórmula proposta por Cho e Slinger (1979):

$C D A_{(n)}=100-\left[100\left(\frac{\% \mathrm{Cr}_{2} \mathrm{O}_{3 r}}{\% C r_{2} O_{3 f}}\right) \times\left(\frac{\% N_{f}}{\% N_{r}}\right)\right]$ (Equação I)

Nesta expressão as variáveis representam: $\operatorname{CDA}(\mathrm{n})$ = Coeficiente de digestibilidade aparente do nutriente da ração; $\% \mathrm{Cr}_{2} \mathrm{O}_{3} \mathrm{r}=\%$ de óxido de crômio-III na ração; $\% \mathrm{Cr}_{2} \mathrm{O}_{3} \mathrm{f}=\%$ de óxido de crômio-III nas fezes; $\mathrm{Nr}=$ Nutrientes na ração; $\mathrm{Nf}=$ Nutriente nas fezes.

Os coeficientes de digestibilidade aparente dos nutrientes e da energia dos ingredientes foram calculados de acordo com a fórmula descrita por Cho e Slinger (1979):

$C D A_{(n)}=\frac{C D A_{R T}-C D A_{R R} \cdot x}{y}$ (Equação II)

Nesta expressão as varáveis representam: $\operatorname{CDA}(n)=$ Coeficiente de digestibilidade aparente do nutriente do ingrediente; $C D A_{R T}=$ Coeficiente de digestibilidade aparente do nutriente na ração 
teste; $C_{D A}=$ Coeficiente de digestibilidade aparente do nutriente na ração referência; $x=$ Proporção da ração referência; $y=$ Proporção da ração teste.

As médias dos coeficientes de digestibilidade aparente dos nutrientes foram submetidas à análise de variância (ANOVA) e o teste de Tukey foi utilizado na comparação das médias. Todas as análises foram realizadas utilizando-se o pacote computacional SISVAR (Versão 5.7), ao nível de 5,0\% de significância.

\section{RESULTADOS E DISCUSSÃO}

Os valores de CDAs e digestíveis das farinhas de subprodutos de abacaxi, manga e maracujá estão contidos na Tabela 2. O coproduto de manga apresentou o maior CDA-MS e o menor CDA$\mathrm{PB}$, enquanto os demais ingredientes foram iguais entre si. Os três ingredientes apresentaram CDAEE e CDA-MM iguais estatisticamente. O CDA-EB do coproduto do maracujá foi estatisticamente inferior aos demais.

Tabela 2 - Coeficientes de digestibilidade aparente (CDAs \pm Desvios padrões) de nutrientes e energia dos farelos dos coprodutos de abacaxi, manga e maracujá para juvenis de tambaqui (Colossoma macropomum).

\begin{tabular}{lrrrr}
\hline \multirow{2}{*}{ CDAs (\%) } & \multicolumn{3}{c}{ Coeficientes de Digestibilidade Aparentes - CADs (\%) } \\
\cline { 2 - 5 } & \multicolumn{1}{c}{ Abacaxi } & \multicolumn{1}{c}{ Manga } & \multicolumn{1}{c}{ Maracujá } & \multicolumn{1}{c}{ CV (\%) } \\
\hline Matéria seca & $57,26 \pm 3,88 \mathrm{c}$ & $69,65 \pm 3,88 \mathrm{a}$ & $30,48 \pm 3,44 \mathrm{c}$ & 7,13 \\
Proteína bruta & $82,26 \pm 3,10 \mathrm{a}$ & $66,61 \pm 0,69 \mathrm{~b}$ & $86,07 \pm 2,74 \mathrm{a}$ & 3,09 \\
Extrato etéreo & $65,41 \pm 11,02 \mathrm{a}$ & $68,87 \pm 9,46 \mathrm{a}$ & $78,40 \pm 10,18 \mathrm{a}$ & 14,44 \\
Matéria mineral & $78,26 \pm 5,17 \mathrm{a}$ & $67,67 \pm 5,18 \mathrm{a}$ & $71,08 \pm 10,45 \mathrm{a}$ & 10,18 \\
Energia bruta & $53,25 \pm 3,11 \mathrm{a}$ & $57,21 \pm 3,30 \mathrm{a}$ & $19,94 \pm 1,97 \mathrm{~b}$ & 6,57 \\
\hline Nutrientes Digestíveis (\%) & \multicolumn{5}{c}{} & - \\
\hline Matéria seca digestível & 57,26 & 69,65 & 30,48 & - \\
Proteína digestível & 5,20 & 3,68 & 8,17 & - \\
Extrato etéreo digestível & 1,15 & 1,51 & 1,55 & - \\
Matéria mineral digestível & 1,91 & 1,53 & 5,39 & - \\
Energia digestível (Kcal/kg) & 2280,78 & 2489,24 & 800,96 & - \\
\hline
\end{tabular}

a, b, c: Valores seguidos por letras diferentes em uma mesma linha são estatisticamente diferentes (Tukey: P<0,05). Os valores médios foram compostos por três repetições. ${ }^{1} \mathrm{CV}=$ Coeficientes de variação. ${ }^{2} \mathrm{Os}$ valores apresentados para os Nutrientes Digestíveis são com base em $100 \%$ de matéria seca.

Ao serem considerados os resultados obtidos em diversos estudos de avaliação de digestibilidade (Tuesta, 2018; Costa et al., 2009; Lousada Júnior et al., 2006) foi possível observar que os valores referentes à composição nutricional dos resíduos da produção de polpas de frutas testados neste estudo apresentaram variação considerável, se comparados a outros produtos com potencial uso na fabricação de rações. Isto se deve principalmente aos diferentes processos de produção pelos quais as frutas são submetidas, consequentemente formando resíduos com proporções variadas de cascas, bagaços fibrosos, caroços e sementes, tornando mais complexa a comparação e análise de resultados destes estudos em comparação aos do presente trabalho. De maneira geral, pode-se afirmar que estes coprodutos são caracterizados por baixos níveis de proteína bruta (não superiores a 10\%) e altos níveis de fibra bruta (não inferiores a 10\%) se forem consideradas como padrão as exigências nutricionais estimadas de tambaquis. 
Em função desta variação na composição nutricional destes coprodutos e da escassez de estudos de digestibilidade utilizando este material como ingrediente para fabricação de ração animal, uma análise comparativa de índices de digestibilidade com outros estudos para peixes se torna um desafio. Na literatura sobre o assunto, encontra-se uma certa diversidade de estudos com estes alimentos, mas estes consideram o desempenho zootécnico dos animais como medida da qualidade nutricional desses coprodutos.

Dentre os estudos disponíveis sobre digestibilidade de nutrientes de coprodutos de frutas, Tuesta (2018) e Costa et al. (2009) obtiveram CDA-MS (51,65 e 89,91\%, respectivamente) e CDAPB (91,35 e 78,12\%, respectivamente) para as farinhas de resíduos de abacaxi, quando utilizadas na alimentação de tilápia do Nilo. Os valores dos CDA-MS $(57,26 \%)$ e de CDA-PB $(82,26 \%)$ do farelo de abacaxi utilizado neste estudo são intermediários aos valores obtidos nos estudos realizados pelos autores supracitados (Tabela 2).

Alguns estudos anteriores avaliaram resíduos de manga, e seus resultados apresentaram CDA variáveis para diversos nutrientes, a citar: CDA-MS: 43,59\% (TUESTA, 2018); 72,78\% (ALMEIDA, 2017) e 63,79\% (COSTA et al., 2009) e CDA-PB: 55,13\% (TUESTA, 2018) ; 78,20\% (ALMEIDA, 2017) e 78,59\%(COSTA et al., 2009). Os resultados obtidos no presente estudo para o farelo de manga (Tabela 2) apresentaram CDA-MS (69,65\%) e CDA-PB (66,61\%) dentro da amplitude dos valores dos estudos anteriores citados. Contudo, ao compararmos o aproveitamento de energia do farelo de manga pelo tambaqui deste estudo (CDA-EB: 57,21\%), em relação ao ensaio conduzido por COSTA et al. (2009), com tilápia do Nilo (CDA-EB: 36,68\%), é possível constatar que a energia deste coproduto é melhor aproveitado pelo tambaqui, se consideramos apenas os valores de digestibilidade deste parâmetro nutricional.

No estudo conduzido por TUESTA (2018) com tilápia-do-Nilo, o resíduo da produção de polpa de maracujá possui digestibilidade superior aos resíduos de abacaxi e manga. Tais resultados diferem substancialmente dos obtidos com o farelo de maracujá desta pesquisa. Este farelo apresentou valores inferiores de digestibilidade de matéria seca e de energia quando comparado aos outros coprodutos testados, apesar de seus valores de CDA-PB e CDA-EE terem sido relativamente altos (Tabela 2 ).

Como normalmente esperado para os ingredientes alternativos, os CDA-MS e os CDA-EB de todos os coprodutos de frutas aqui estudados são inferiores aos do milho $(77,8$ e $76,4 \%)$ e da quirera de arroz (83,8 e 80,7\%) apresentados por Guimarães et al. (2014) para tambaquis. É importante salientar que estes seriam os ingredientes passíveis de substituição em caso de uso dos coprodutos de frutas em dietas comerciais para peixes. No trabalho de Bicudo et al. (2018), também é possível observar que os CDAs dos ingredientes alternativos para o híbrido tambacu (Colossoma macropomum $\times$ Piaractus mesopotamicus) foram, em geral, inferiores aos obtidos para os ingredientes tradicionais o que, de certa maneira, justifica os baixos CDAs dos coprodutos no presente estudo.

Em seu estudo, Tuesta (2018) afirma que diferentes tipos de fibra, solúveis ou insolúveis, interferem no tempo de trânsito intestinal do alimento e na capacidade de retenção de água e atribui a alta digestibilidade dos nutrientes do farelo de maracujá à presença de fibras altamente fermentáveis (pectina e mucílagos). Neste sentido, Lousada Júnior et al. (2006) obtiveram valores 
de pectina de $24,98 \%$ para o maracujá. Com relação aos efeitos do tipo de fibra sobre a digestibilidade em tambaquis, Silva et al. (2003), analisando frutos e sementes que possuíam de 3,0 a $28,5 \%$ de FB, afirmaram que esta espécie é hábil em digerir alguns alimentos ricos em fibras. Além disto, os mesmos autores analisaram o trânsito intestinal das dietas, que continuam diferentes teores de FB e estas apresentaram a mesma velocidade de trânsito no trato digestivo. Diante destas informações é possível entender as prováveis razões para o farelo de resíduo de manga utilizado no presente estudo, mesmo possuindo cerca de $40 \%$ de FB, apresentou valores relativamente adequados de CDAs. Contudo, de acordo com as afirmações de Guimarães et al. (2014), o mecanismo pelo qual os tambaquis conseguem digerir carboidratos complexos ainda necessita ser melhor estudado, até então não se pode realizar inferência que possa explicar os baixos valores de digestibilidade para o farelo de maracujá em comparação ao farelo de manga.

Zanetti et al. (2018), estudando os efeitos da inclusão do farelo de sementes de maracujá em rações sobre o desempenho zootécnico de frangos de corte, observaram piora da conversão alimentar (variável diretamente relacionada ao aproveitamento dos nutrientes da dieta) em animais que consumiram rações com os maiores níveis deste coproduto. A explicação dada pelos autores para justificar este resultado é que as fibras do ingrediente podem ter efeito diluidor dos demais nutrientes e, ainda, funcionar como fator antinutricional. Ainda que Tuesta (2018) e Zanetti et al. (2018) apresentem informações contrastantes sobre os efeitos do consumo de coprodutos oriundos da produção de polpas de maracujá, não obstante ao fato de os últimos autores terem utilizado aves como modelo animal para o seu estudo, sua inferência é a mais apropriada para descrever o fenômeno de baixo aproveitamento de nutrientes deste ingrediente no presente estudo, não sendo a única possível.

No sentido de analisar outras possíveis causas para os baixos CDAs dos nutrientes do farelo de maracujá, pode-se incluir na análise que, para Nascimento et al. (2013), embora os produtos à base de plantas sejam geralmente considerados seguros, sua toxicidade não deve ser descartada devido aos constituintes cianogênicos de diversas espécies, como por exemplo, das passifloras. Os mesmos autores, analisando pesquisas com humanos destacam que, para a casca de maracujá, existem poucos estudos com relação à sua toxicidade in vivo. Nos estudos com humanos, onde a farinha de albedo da fruta é utilizada na alimentação para a verificação de efeitos sobre índices glicêmicos e lipídicos, as quantidades consumidas são proporcionalmente muito inferiores àquelas adotadas para os peixes do presente estudo, $30 \%$ do total de alimento ingerido pelos animais do tratamento específico, o que, obviamente, agravaria possíveis efeitos tóxicos sobre a capacidade de aproveitamento dos nutrientes pelos peixes. Entretanto, aqui se trata apenas de uma possibilidade que se agruparia a uma série de outros fatores, sendo necessário destacar que não houve nenhuma mortalidade ou qualquer sinal clínico que suscitasse aos autores apontarem para ocorrência de intoxicação dos animais.

\section{CONCLUSÃO}

Ainda que tenha havido boa digestibilidade da proteína bruta das farinhas de subprodutos de frutas, os baixos valores de energia digestível, principalmente para o maracujá, somados aos altos níveis de fibra bruta, podem consistir em fatores limitantes ao uso destes ingredientes nas 
rações de peixes. Assim, ainda que as farinhas aqui estudadas possam ser utilizadas, em alguma medida, para compor dietas de tambaquis, recomenda-se a busca pela adequação às exigências nutricionais da espécie, principalmente no uso de coprodutos de maracujá. Entretanto, são necessários outros testes de digestibilidade com peixes em diferentes estágios de desenvolvimento, assim como ensaios de desempenho zootécnico para auferir outras respostas biológicas que possibilitem melhor ponderação sobre as recomendações de uso destes ingredientes para a alimentação de tambaquis.

\section{AGRADECIMENTOS}

Os autores agradecem ao CNPQ pelo financiamento da pesquisa (Projeto № 488122/20139 - Chamada MEC/SETEC/CNPq № 94/2013), à Multifrutas (Agricom Agro Indústria e Comércio Anadiense Ltda) pela doação dos subprodutos e suporte logístico, à UFAM e ao IFAL pelas bolsas de Iniciação Científica concedidas e pelo apoio à pesquisa.

\section{REFERÊNCIAS}

ALMEIDA, A.C.A. (2017) Digestibilidade aparente de resíduos de frutas para o tambaqui (Colossoma macropomum). DISSERTAÇÃO (Mestrado em Zootecnia). Universidade Federal de Sergipe, $47 p$.

KIST, B.B.; CARVALHO, C.; TREICHEL, M.; SANTOS, C.E. Anuário Brasileiro da Fruticultura 2018. Santa Cruz do Sul: Editora Gazeta Santa Cruz, 2018. 88 p. 2018. Disponível em: <http://www.editoragazeta.com.br/sitewp/wpcontent/uploads/2018/04/FRUTICULTURA_2018_dupla.pdf>. Acessado em: 26 dez. 2019.

ASSOCIATION OF OFFICIAL ANALYTICAL CHEMISTS (AOAC). (2005) Oficcial methods of analysis of AOAC International. AOAC. 18th Edition.

BICUDO, A.J.A.; ARAUJO, T.A.T.; BRAGA, L.G.T.; TONINI, W.C.T.; HISANO, H. (2018) Apparent digestibility of conventional and alternative feedstuffs by hybrid tambacu juveniles. Anais da Academia Brasileira de Ciências, 90(1): 471-478.

BREMER NETO, H., GRANER, C.A.F., PEZZATO, L.E. (2005) The spectrophotometric method on the routine of 1,5-diphenylcarbazide was adjusted on chromium determination in feces, after its utilization as a biological marker as chromium (III) oxide. Ciência Rural, 25(3): 691-697.

CHO, C.Y.; SLINGER, S.J. (1979) Apparent digestibility measurements in feedstuffs for rainbow trout. In: HALVER, J.E. \& TIEWS. Finfish nutrition and fishfeed technology, Berlin: Proceedings of the World Symposium of Finfish Nutrition and Fishfeed Technology, Vol.2, p.239-247.

COSTA, W. M.; LUDKE, M. C. M. M.; BARBOSA, J. M.; HOLANDA, M A.; SANTOS, E. L.; RICARTE, M. (2009) Digestibilidade de nutrientes e energia de resíduos de frutas pela tilápia do Nilo (Oreochromis niloticus). In: REUNIÃO ANUAL DA SOCIEDADE BRASILEIRA DE ZOOTECNIA, 46, 2009, Paraná. Anais... Maringá: [s.n.] 2009. p.1-3. (Resumo Expandido) 
GUIMARÃES, I.G.; MIRANDA, E.C.; ARAÚJO, J.G. (2014) Coefficients of total tract apparent digestibility of some feedstuffs for Tambaqui (Colossoma macropomum). Animal Feed Science and Technology, 188(1): 150-155.

IBGE. Produção da pecuária municipal 2015. (2015) Instituto Brasileiro de Geografia e Estatística. Rio de Janeiro, v.43, 49p.

LOUSADA JUNIOR, J.E.; NEIVA, J.N.N.; RODRIGUEZ, N.M.; COSTA, J.M.C. (2006) Caracterização físico-química de subprodutos obtidos do processamento de frutas tropicais visando seu aproveitamento na alimentação animal. Revista Ciência Agronômica, 37(1): 70-76.

NASCIMENTO, E.M.G.C.; ASCHERI, J.L.R.; CARVALHO, C.W.P.; GALDEANO, M.C. (2013) Benefícios e perigos do aproveitamento da casca de maracujá (Passiflora edulis) como ingrediente na produção de alimentos. Revista do Instituto Adolfo Lutz, 72(3): 1-11.

SILVA, J.A.M.; PEREIRA FILHO, M.; OLIVEIRA-PEREIRA, M.I. (2003) Fruits and seeds consumed by tambaqui (Colossoma macropomum CUVIER, 1818) incorporated in the diets. Gastrointestinal tract digestibility and transit velocity. Revista Brasileira de Zootecnia, 32(6): 1815-1824.

TUESTA, M.G.R. (2018) Valor nutricional de coprodutos da indústria de polpa de frutas e níveis de inclusão em rações de tilápia do Nilo (Oreochromis niloticus). TESE (Doutorado em Zootecnia). Universidade Federal de Viçosa, 93p.

ZANETTI, L.H.; MURAKAMI, A.E.; DIAZ-VARGAS, M.; GUERRA, A.F.Q.G.; OSPINA-ROJAS, I.C.; NASCIMENTO, G.R.; SANTOS, T.C.; PINTRO, P.T.M. (2018) By-product of passion fruit seed (Passiflora edulis) in the diet of broilers. Canadian Journal of Animal Science, 98(1): 109-118.

\section{COMO CITAR ESTE ARTIGO:}

Araujo, D. de M., Bordinhon, A. M., Fujimoto, R. Y., Silva, W. M. da, Silva, D. R. da, Silva, J. da. (2020). Digestibilidade de farinhas de coprodutos de abacaxi, manga e maracujá pelo tambaqui (Colossoma macropomum). Holos. 36(5), 1-10.

\section{SOBRE OS AUTORES}

\section{M. ARAUJO}

Doutor em Zootecnia. Programa de Pós-Graduação em Tecnologias Ambientais do Instituto Federal de Alagoas (PPGTEC - IFAL).E-mail: daniel.araujo@ifal.edu.br ORCID ID: https://orcid.org/ 0000-0003-0700-9836

\section{A. M. BORDINHON}

Doutor em Zootecnia. Programa de Pós-graduação em Ciências Ambientais - PPGCA. Instituto de Educação, Agricultura e Ambiente - IEAA. Universidade Federal do Amazonas (UFAM). E-mail: ambordinhon@gmail.com.

ORCID ID: https://orcid.org/ 0000-0003-3103-6201

\section{R. Y. FUJIMOTO}

Doutor em Zootecnia. Pesquisador da EMBRAPA Tabuleiros Costeiros. Programa de Pós-Graduação em Ciência Animal (UFPA). Programa de Pós-Graduação em Saúde e Ambiente (UNIT). EMBRAPA Tabuleiros 
Costeiros. E-mail: rodrigo.fujimoto@embrapa.br

ORCID ID: https://orcid.org/ 0000-0002-5039-4445

W. M. DA SILVA

Graduando em Agronomia. Universidade Federal do Amazonas (UFAM). E-mail: williammaciel1992@outlook.com

ORCID ID: https://orcid.org/0000-0003-2132-8673

D. R. DA SILVA

Licenciado em Biologia pelo IFAL. Mestre em Aquicultura pelo Centro de Aquicultura da UNESP. E-mail: dnesonrichard01@gmail.com

ORCID ID: https://orcid.org/ 0000-0001-9502-5064

\section{J. DA SILVA}

Licenciada em Biologia pelo IFAL. Mestre em Aquicultura pelo Centro de Aquicultura da UNESP. E-mail: biologiajoseane@gmail.com

ORCID ID: https://orcid.org/0000-0003-4208-6116

Editor(a) Responsável: Francinaide de Lima Silva Nascimento

Pareceristas Ad Hoc: Arivonaldo Da Silva e Odisséia Gaspareto

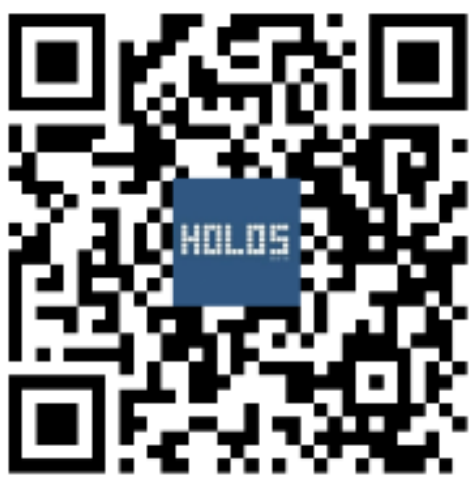

